\title{
How do patients with a Turkish background evaluate their medical care in Germany? An observational study in primary care
}

This article was published in the following Dove Press journal:

Patient Preference and Adherence

3 November 2015

Number of times this article has been viewed

\author{
Katja Goetz' \\ Jessica Bungartz ${ }^{2}$ \\ Joachim Szecsenyi' \\ Jost Steinhaeuser ${ }^{3}$ \\ 'Department of General Practice \\ and Health Services Research, \\ University of Heidelberg, Heidelberg, \\ Germany; ${ }^{2}$ Praxis Medizin im Zentrum, \\ München, Germany; ${ }^{3}$ Institute of \\ Family Medicine, University Hospital \\ Schleswig-Holstein, Lübeck, Germany
}

Correspondence: Katja Goetz

Department of General Practice and

Health Services Research, University of

Heidelberg, Vosstr 2, Building 37, 69II5

Heidelberg, Germany

Tel +49622I 568129

Fax +496221561972

Email katja.goetz@med.uni-heidelberg.de
Background: Patients' evaluation of medical care is an essential dimension of quality of care and an important aspect of the feedback cycle for health care providers. The aim of this study was to document how patients with a Turkish background evaluate primary care in Germany and determine which aspects of care are associated with language abilities.

Methods: The study was based on an observational design. Patients with a Turkish background from German primary care practices completed the EUROPEP (European Project on Patient Evaluation of General Practice Care) questionnaire consisting of 23 items. Seventeen primary care practices were involved with either German ( $\mathrm{n}=8$ ) or Turkish ( $\mathrm{n}=9)$ general practitioners (GPs). Results: A convenience sample of 472 patients with a Turkish background from 17 practices participated in the study (response rate 39.9\%). Practices with a German GP had a lower response rate $(19.6 \%)$ than those with a Turkish GP $(57.5 \%)$. Items evaluated the highest were "keeping data confidential" (73.4\%) and "quick services for urgent health problems" (69.9\%). Subgroup analysis showed lower evaluation scores from patients with good or excellent German language abilities. Patients who consulted a Turkish GP had higher evaluation scores.

Conclusion: The evaluation from patients with a Turkish background living in Germany with either Turkish or German GPs showed lower scores than patients in other studies in Europe using EUROPEP. However, our results had higher evaluation scores than those of Turkish patients evaluating GPs in Turkey. Therefore, different explanation models for these findings should be explored in future studies.

Keywords: migrant health, quality of care, primary health care, patient satisfaction, patient evaluations

\section{Introduction}

Patients' evaluation of medical care is an essential dimension of quality of care and consists of a combination of both patient expectations with regard to health care providers as well as actual patient experience. ${ }^{1}$ It is also an important aspect of the feedback cycle in quality assurance to identify opportunities for improvement. ${ }^{2,3}$ In primary care settings in Germany, general practitioners (GPs) belong to the most frequented group of physicians. Over $90 \%$ of the population consults a GP annually. Increasingly, in Germany, the position of GPs as coordinators of care has been emphasized in recent years. ${ }^{4}$ GPs have contact with different groups of patients including those who have an immigrant background in their daily practice. ${ }^{5}$

Almost 16 million people in Germany have a migrant background with 2.5 million Turkish people being the largest group of migrants. ${ }^{6}$ If they are legal immigrants they could have a health insurance. Furthermore, migrants have a lower utilization of health services than the German nationals. The health care of this population group 
is mostly influenced by socioeconomic factors (eg, lower educational level) and the access to health care could be limited due to language problems but also due to cultural aspects. ${ }^{7}$ However, quality of care for migrant patients has been shown to be underdeveloped combined with an enormous research gap. ${ }^{8}$ It has been shown that quality of primary health care for Turkish immigrants is below that of German nationals..$^{9,10}$ There is a research gap on the perspective of Turkish patients regarding their medical encounter with the GPs.

The aim of this exploratory study was to document how patients with a Turkish background evaluate their primary care in Germany and determine which aspects of care are associated with language abilities.

\section{Methods}

\section{Design and participants}

This study was based on an observational design in which patients with a Turkish background from 17 GP practices completed a questionnaire. Eight GPs were German and nine GPs had a Turkish background (and therefore, could communicate with the patient in Turkish fluently). Participating German GPs represented a convenience sample and were recruited due to personal contact whereas GPs with a Turkish background were identified via the register of the National Association of Statutory Health Insurance Physicians (Kassenärztliche Vereinigung). In all, 143 GPs with a Turkish background were invited to participate in our study by mail. An inclusion criterion for the Turkish GPs was to speak with the patient in Turkish fluently.

Inclusion criteria for the patients were: age over 18 years, sufficient Turkish competence to answer the written questionnaire without support, and formerly known in the practice (no casual patients). Patient participation was voluntary and anonymous. Patients were invited to participate at the GP reception desk to fill in the questionnaire in the waiting room and to put it in a sealed box. The box was subsequently forwarded to the research department. Data collection took place in July and August 2011. The return of the anonymous paper-based questionnaire was classified as informed consent. Because of the recruitment procedure, the participating GP practices were located in four different federal states in Germany (Bavaria, Baden-Wuerttemberg, Lower Saxony, and North Rhine-Westphalia).

\section{Ethics}

The ethics committee of the University Hospital Heidelberg informed us that approval by an ethics committee was not necessary for this observational study. The questionnaires were completed anonymously. No identifying information or data from patients were collected.

\section{Instrument}

The validated Turkish version of the EUROPEP (European Project on Patient Evaluation of General Practice Care) questionnaire was used. ${ }^{11}$ The EUROPEP is an established and internationally validated instrument reflecting a set of indicators for patients to evaluate the quality of primary care. ${ }^{12}$ This questionnaire is a multidimensional instrument that comprises 23 items consisting of five dimensions: "relationship and communication", "medical care", "information and support", "continuity and cooperation", and "availability and accessibility". Patients were asked to evaluate care that they received in the previous 12 months by means of a 5-point Likert scale ranging from "poor" (1) to "excellent" (5) for each item. Additionally, the questionnaire included 11 questions on demographic characteristics (eg, education

Table I Characteristics of patients $(n=472) *$

\begin{tabular}{|c|c|c|}
\hline Characteristics & Number & Percent \\
\hline \multicolumn{3}{|l|}{ Sex } \\
\hline Men & 220 & 46.6 \\
\hline Women & 252 & 53.4 \\
\hline \multicolumn{3}{|l|}{ Age, years } \\
\hline $18-40$ & 226 & 47.9 \\
\hline $41-59$ & 175 & 37.1 \\
\hline$\geq 60$ & 47 & 10.0 \\
\hline \multicolumn{3}{|l|}{ Highest level of education } \\
\hline No school attendance & 15 & 3.2 \\
\hline "Grundschule", primary school & $|2|$ & 25.6 \\
\hline "Hauptschule", secondary school & 93 & 19.7 \\
\hline High school & 195 & 41.3 \\
\hline More than high school & $4 I$ & 8.7 \\
\hline \multicolumn{3}{|l|}{ Nationality } \\
\hline German & 105 & 22.2 \\
\hline Turkish & 357 & 75.6 \\
\hline \multicolumn{3}{|l|}{ Self-reported residence status } \\
\hline Limited & 45 & 9.5 \\
\hline Unlimited & 406 & 86.0 \\
\hline \multicolumn{3}{|l|}{ Self-reported language abilities } \\
\hline Excellent & 127 & 26.9 \\
\hline Good & 98 & 20.8 \\
\hline Medium & 194 & 41.1 \\
\hline Poor & 46 & 9.7 \\
\hline Very poor & 5 & 1.1 \\
\hline \multicolumn{3}{|c|}{ Number of visits to a general practitioner (per year) } \\
\hline $1-4$ & 189 & 40.0 \\
\hline $5-8$ & 129 & 27.3 \\
\hline $9-12$ & 78 & 16.5 \\
\hline$>12$ times & 65 & 13.8 \\
\hline \multicolumn{3}{|l|}{ Start of seeing a general practitioner } \\
\hline Less than I year & 45 & 9.5 \\
\hline Between I and 4 years & 126 & 26.7 \\
\hline Between 5 and 10 years & 142 & 30.1 \\
\hline More than 10 years & 146 & 30.9 \\
\hline
\end{tabular}

Note: ${ }^{n}$ varies due to missing values. 
level, parental birthplace, German language ability) (Table 1). These are based on the basic set of indicators for mapping migrant status developed by Schenk et al. ${ }^{13}$

\section{Data analysis}

Analyses were performed using SPSS 20.0 (SPSS Inc., IBM Corporation, Armonk, NY, USA). Continuous data were summarized using means and standard deviations. Categorical data were presented as frequency counts and percentages. The proportion of all Turkish patients and Turkish patients with good or excellent German language abilities who answered with a category 5 (excellent) of the items of EUROPEP was reported. The comparison of the nationality of GPs (Turkish or German) regarding the evaluation of care from Turkish patients was analyzed with the nonparametric Mann-Whitney $U$-test. Furthermore, the mean scores for each of the five domains (relationship and communication, medical care, information and support, continuity and cooperation, and facilities availability and accessibility) were computed. Moreover, a linear regression analysis was performed for the whole study population. The self-reported language ability was the outcome variable and the five domains of EUROPEP, the characteristics of participating practices, GPs of these practices (sex and nationality of GP), and patients (age, sex, number of visits to the GP per year and the point of time patients started seeing a GP) were potential predictors. An $\alpha$ level of $P<0.05$ was used for tests of statistical significance.

\section{Results}

In total, data from 17 practices $(85 \%)$ were collected. From 1,190 patient questionnaires that were handed out, 472 were returned, which resulted in a response rate of $39.9 \%$. Practices with a German GP (eight practices) showed a considerably lower response rate (19.6\%) than practices with a Turkish GP (nine practices) $(57.5 \%)$. The mean age of the patients was 40.7 years (ranging between 18 and 92 years). The mean age of the GPs was 51.2 years (ranging between 37 and 66 years). The characteristics of the participating patients and GPs are illustrated in Tables 1 and 2.

\section{Patients' evaluation of primary care}

Table 3 shows the descriptive results of Turkish patients' evaluation of their health care for each item of the EUROPEP questionnaire, including the proportion of patients who answered a category 5 (excellent). The number of missing values was negligible. Most of the positive ratings were given for the domain "relationship and communication" ("listening
Table 2 Characteristics of general practitioners $(n=17)$

\begin{tabular}{lll}
\hline Characteristics & Number & Percent \\
\hline Sex & 13 & \\
$\quad$ Men & 4 & 76.5 \\
$\quad$ Women & & 23.5 \\
Age, years & 2 & \\
$\quad<40$ & 4 & 11.8 \\
$40-49$ & 6 & 23.5 \\
$50-60$ & 5 & 35.3 \\
$\quad>60$ & & 29.4 \\
Nationality & 8 & \\
$\quad$ German & 9 & 47.1 \\
$\quad$ Turkish & & 52.9 \\
Mode of practice & 12 & 70.6 \\
$\quad$ Solo & 5 & 29.4 \\
$\quad$ Group practice & & 82.4 \\
Location of practice & 14 & 17.6 \\
$\quad \geq 15,000$ inhabitants & 3 & \\
$\quad<15,000$ inhabitants &
\end{tabular}

to you", $69.2 \%$; "keeping your records and data confidential", $73.4 \%$ ) and for the domain "medical care" ("thoroughness", 66.4\%; "physical examination", 67.2\%). The most negative perceptions were found in the domain "availability and accessibility" ("being able to speak to the GP on the telephone", $46.8 \%$ and "waiting time in the waiting room", $31.1 \%$ ).

The evaluation scores of patients with good or excellent German language abilities were lower than those of other participants. The results of the subgroup analysis for patients attending GPs of either German or Turkish nationality, including mean, standard deviation, and $P$-values of the EUROPEP, are given in Table 4.

Overall, nearly $75 \%$ of the participants with poor German language abilities visited Turkish GPs. Table 4 shows statistically significant differences within almost all items of EUROPEP when comparing patients consulting a Turkish GP with those consulting a German GP.

Table 5 shows the linear regression analysis of the study population characteristics and the five domains of EUROPEP on language abilities of patients. The model explained $35 \%$ $\left(R^{2}=0.352\right)$ of the variance on the dependent variable "selfreported language ability". Significant associations were found for two domains of EUROPEP questionnaire: "information and support" and "continuity and cooperation". Patients with poorer language abilities were older and visited the GP more often and their "information and support" domain was worse, but interestingly "continuity and cooperation" was rated better than that of patients with better language abilities (self-reported).

\section{Discussion}

The aim of this pilot study was to evaluate the care experiences reported by patients with a Turkish background living 
Table 3 Evaluation of care by Turkish patients $(n=357)$

\begin{tabular}{|c|c|c|}
\hline EUROPEP questionnaire & $\begin{array}{l}\text { Percentage } \\
\text { of all patients } \\
(\mathrm{n}=357)^{*}\end{array}$ & $\begin{array}{l}\text { Percentage of patients with } \\
\text { good or excellent German } \\
\text { language abilities }(n=153)^{*}\end{array}$ \\
\hline \multicolumn{3}{|l|}{ Relationship and communication } \\
\hline I. Making you feel you had time during consultations & 49.3 & 42.5 \\
\hline 2. Interest in your personal situation & 57.4 & 53.6 \\
\hline 3. Making it easy to tell about your problems & 57.4 & 49.7 \\
\hline 4. Involving you in decisions about medical care & 51.8 & 48.4 \\
\hline 5. Listening to you & 69.2 & 64.1 \\
\hline 6. Keeping your records and data confidential & 73.4 & 70.6 \\
\hline \multicolumn{3}{|l|}{ Medical care } \\
\hline 7. Quick relief of your symptoms & 49.3 & 43.8 \\
\hline 8. Helping to perform your normal daily activities & 51.3 & 44.4 \\
\hline 9. Thoroughness & 66.4 & 58.2 \\
\hline 10. Physical examination & 67.2 & 60.8 \\
\hline II. Offering you services for prevention & 59.1 & 54.9 \\
\hline \multicolumn{3}{|l|}{ Information and support } \\
\hline 12. Explaining the purpose of tests and treatments & 63.0 & 58.2 \\
\hline 13. Telling about your symptoms and/or illness & 64.1 & 57.5 \\
\hline 14. Help in dealing with emotional problems & 54.1 & 49.7 \\
\hline 15. Helping understand the importance of following advice & 55.2 & 46.4 \\
\hline \multicolumn{3}{|l|}{ Continuity and cooperation } \\
\hline 16. Knowing what has been done during previous contacts & 54.9 & 47.7 \\
\hline 17. Preparing what to expect from specialists & 54.3 & 45.8 \\
\hline \multicolumn{3}{|l|}{ Facilities availability and accessibility } \\
\hline 18. The helpfulness of the staff & 59.4 & 50.3 \\
\hline 19. Getting an appointment to suit you & 62.7 & 55.6 \\
\hline 20. Getting through to the practice on telephone & 63.3 & 58.2 \\
\hline 21. Being able to speak to the GP on the telephone & 46.8 & 41.8 \\
\hline 22. Waiting time in the waiting room & 31.1 & 28.1 \\
\hline 23. Quick services for urgent health problems & 69.9 & 52.9 \\
\hline
\end{tabular}

Note: *With answer 5 (excellent).

Abbreviations: EUROPEP, European Project on Patient Evaluation of General Practice Care; GP, general practitioner.

in Germany and determine which EUROPEP domains were associated with patients' language abilities. In general, patients were very positive about their care with the exception of "waiting time in the waiting room". This finding is comparable with another study using EUROPEP in Germany. ${ }^{14}$

Both dental care and primary care patients showed the lowest satisfaction level regarding the item "waiting time in the waiting room". ${ }^{14,15}$ Similar results were shown for patient satisfaction in Slovenia. ${ }^{16}$

Moreover, a study about patient satisfaction with family practice in Turkey showed the lowest satisfaction regarding "being able to speak to the GP on the telephone" and "getting through to the practice on the phone". ${ }^{17}$ These results are comparable to our study for patients with poor German language skills.

In subgroup analysis, language abilities showed the greatest impact on the factor of patient satisfaction. Patients with poor German language skills consulted a Turkish GP most frequently (75\%). According to our subgroup analysis, there were several interpretation levels. Turkish GP visits were associated with higher satisfaction rates (Table 4). These findings reflect the effect of ethnic doctor-patient concordance on patient satisfaction. ${ }^{18,19}$

However, there is another important aspect related to German language ability. In our study, patients with good or excellent German language abilities showed overall less satisfaction in the whole study population. These findings were surprising because the impact of communicational barriers on effective doctor-patient interaction has been widely discussed. ${ }^{20,21}$ It was anticipated that patients with good German language abilities would adapt and reflect the German patients in the study population, as it was found for other aspects of medical care, for example, the utilization of health services. ${ }^{22}$ It could be assumed that patients who are able to communicate on an equal level could be more critical and more discerning about health care providers. Moreover, apart from communication problems, other factors in the doctor-patient encounter could have an impact on treatment 
Table 4 Turkish patients' perspective on care: a comparison of Turkish and German GPs

\begin{tabular}{|c|c|c|c|c|c|}
\hline \multirow[t]{3}{*}{ EUROPEP questionnaire } & \multicolumn{4}{|c|}{ Nationality of GP } & \multirow[t]{3}{*}{ P-value* } \\
\hline & \multicolumn{2}{|c|}{ German } & \multicolumn{2}{|c|}{ Turkish } & \\
\hline & $\mathbf{n}$ & Mean (SD) & $\mathbf{n}$ & Mean (SD) & \\
\hline \multicolumn{6}{|l|}{ Relationship and communication } \\
\hline I. Making you feel you had time during consultations & 108 & $4.0(1.10)$ & 346 & $4.14(1.07)$ & 0.18 \\
\hline 2. Interest in your personal situation & 108 & $3.96(1.31)$ & 347 & $4.31(1.07)$ & 0.009 \\
\hline 3. Making it easy to tell about your problems & 109 & $3.99(1.36)$ & 342 & $4.40(0.90)$ & 0.009 \\
\hline 4. Involving you in decisions about medical care & 106 & $4.08(1.18)$ & 333 & $4.30(1.02)$ & 0.06 \\
\hline 5. Listening to you & 108 & $4.22(1.20)$ & 351 & $4.52(0.90)$ & 0.02 \\
\hline 6. Keeping your records and data confidential & 108 & $4.25(1.26)$ & 343 & $4.59(0.93)$ & 0.007 \\
\hline \multicolumn{6}{|l|}{ Medical care } \\
\hline 7. Quick relief of your symptoms & 107 & $3.96(1.31)$ & 337 & $4.16(1.17)$ & 0.15 \\
\hline 8. Helping to perform your normal daily activities & 106 & $3.93(1.32)$ & 338 & $4.20(1.17)$ & 0.04 \\
\hline 9. Thoroughness & 107 & $4.22(1.17)$ & 348 & $4.50(0.86)$ & 0.048 \\
\hline 10. Physical examination & 109 & $4.25(1.13)$ & 346 & $4.52(0.89)$ & 0.03 \\
\hline II. Offering you services for prevention & 107 & $4.06(1.26)$ & 336 & $4.43(1.01)$ & 0.002 \\
\hline \multicolumn{6}{|l|}{ Information and support } \\
\hline 12. Explaining the purpose of tests and treatments & 105 & $4.18(1.23)$ & 335 & $4.46(0.97)$ & 0.02 \\
\hline 13. Telling about your symptoms and/or illness & 106 & $4.19(1.18)$ & 348 & $4.51(0.88)$ & 0.006 \\
\hline 14. Help in dealing with emotional problems & 106 & $3.82(1.52)$ & 342 & $4.30(1.11)$ & 0.003 \\
\hline 15. Helping understand the importance of following advice & 107 & $4.06(1.31)$ & 337 & $4.41(0.88)$ & 0.03 \\
\hline \multicolumn{6}{|l|}{ Continuity and cooperation } \\
\hline 16. Knowing what has been done during previous contacts & 105 & $3.98(1.37)$ & 343 & $4.34(0.95)$ & 0.06 \\
\hline I7. Preparing what to expect from specialists & 108 & $3.90(1.43)$ & 331 & $4.31(1.13)$ & 0.005 \\
\hline \multicolumn{6}{|l|}{ Facilities availability and accessibility } \\
\hline 18. The helpfulness of the staff & 108 & $3.95(1.28)$ & 337 & $4.34(1.20)$ & $<0.001$ \\
\hline 19. Getting an appointment to suit you & 107 & $3.92(1.32)$ & 346 & $4.33(1.22)$ & $<0.001$ \\
\hline 20. Getting through to the practice on telephone & 109 & $3.90(1.34)$ & 340 & $4.37(1.16)$ & $<0.00$ I \\
\hline 2I. Being able to speak to the GP on the telephone & 107 & $3.57(1.57)$ & 319 & 3.95 (I.49) & 0.006 \\
\hline 22. Waiting time in the waiting room & 107 & $3.4 \mathrm{I}(1.39)$ & 338 & $3.68(1.38)$ & 0.04 \\
\hline 23. Quick services for urgent health problems & 109 & $4.00(1.46)$ & 340 & $4.39(1.13)$ & 0.005 \\
\hline
\end{tabular}

Note: $* P<0.05$.

Abbreviations: GPs, general practitioners; SD, standard deviation.

Table 5 Associations of the study population characteristics and the five domains of EUROPEP on language abilities (results of the linear regression analysis, under specification of standardized $\beta$-coefficient, $\alpha=5 \%$ )

\begin{tabular}{lll}
\hline Associated items & $\beta$-coefficient & $P$-value* \\
\hline Domains of EUROPEP questionnaire & & \\
Relationship and communication & 0.027 & 0.728 \\
Medical care & -0.016 & 0.841 \\
Information and support & -0.175 & 0.039 \\
Continuity and cooperation & 0.193 & 0.005 \\
Facilities availability and accessibility & 0.031 & 0.585 \\
Practice and GP characteristics & & \\
Type of practice & 0.060 & 0.212 \\
Nationality of GP & 0.024 & 0.617 \\
Sex of GP & -0.074 & 0.132 \\
Age of GP & -0.115 & 0.018 \\
Patient characteristics & & \\
Sex & 0.106 & 0.009 \\
Age & 0.496 & $<0.001$ \\
Number of visits to the GP per year & 0.177 & $<0.001$ \\
The point of time patients started & 0.004 & 0.926 \\
seeing a GP & & \\
$R^{2}$ & 0.352 & \\
\hline
\end{tabular}

Note: $* P<0.05$.

Abbreviation: GP, general practitioner. as perceived by these patients. Racial or ethnic discrimination in health care has already been discussed and identified as an important but variable factor in medical encounters. ${ }^{23}$ Too little is known about patients' perspectives and experiences with German GPs.

Results from the regression analysis showed that patients with poorer German language abilities evaluated their "information and support" lower but "continuity and cooperation" better than that of patients with better German language abilities. Information about treatment or understanding the importance of following advice is an important component within a doctor-patient interaction. This needs more attention for patients with poorer language abilities. Furthermore, continuity and cooperation are very important not only for patients with long-term or chronic conditions, but also with poorer language abilities. ${ }^{24}$ More research is needed to evaluate the meaning and consequences of continuity and cooperation for patients with poorer language abilities.

These results could be also associated with a cultural understanding and interpretation of the medical encounter 
and expectations toward the GP that will differ from other European countries. Previous studies showed that patients' experiences are related to expectation rather than to GP performance. ${ }^{25,26}$ In Turkey, great respect is given to doctors based on a more hierarchical perception of the doctor as a "learned man". ${ }^{27}$ It can be assumed that children of second and third generation migrants could also apply this interaction model inherited from their parents. It could also be assumed that high expectations cannot be fulfilled by GPs for multiple reasons (such as lack of time, different understandings of illness and treatment) or even paradigm shifts as the ideal of the omnipotent physician falls apart in modern society, which all lead to lower patient satisfaction rates. Overall, more research is needed to further explore the importance of this aspect. ${ }^{28}$

\section{Strengths and limitations}

A major strength of this study is the utilization of the patients' native language in the questionnaire. Many surveys exclude foreign language-speaking patients for methodological reasons, meaning little is known about the needs and wishes of these patient groups. The study is limited by the overall low return rate of questionnaires from practices with German GPs. Due to the small number of participating practices, the results of this study cannot be seen as representative for Germany. A selection bias may have been introduced through the mode of recruiting the practices and participating patients. We did not assess the health condition of the participating patients. However, we compared our data with evaluations of European patients with chronic diseases. Since previous studies showed associations with chronic conditions and lower patient satisfaction rates, ${ }^{29,30}$ results of direct comparisons need to be interpreted carefully. Nevertheless, we oriented our study design, performance, and data analysis strongly to previous EUROPEP studies. ${ }^{14,15}$ Following the analysis of EUROPEP in other studies, only the numbers scoring " 5 " were reported. ${ }^{14,15}$ In general, the EUROPEP shows a ceiling effect not only in our study but also in previous studies. ${ }^{14,15}$ There is no cut-off of the EUROPEP tool for clinically significant differences available. Moreover, we believe that the developed hypotheses and theories can implicate important new aspects and views of patients with a Turkish background to their primary care.

\section{Conclusion}

Satisfaction with primary care of patients with a Turkish background is, in this study, overall lower than in comparable EUROPEP studies in Europe, though higher than satisfaction rates in Turkey itself. These findings indicate differences in perceived quality of care based on several levels and different aspects of primary care (health care system, doctor/ staff-patient relationship, culture, language abilities) that need further research. Particular attention should be paid to the influence of German language skills. Though good or excellent language competencies seem to equalize ethnical doctor-patient discordance, German-speaking patients were overall less satisfied with the received health care. In the context of the ongoing debate about how effective practice in health care for migrant patients should be implemented, these results could raise issues that need attention in the German health care policy. Given the current situation of migration to Germany, it is important to evaluate the actual needs of patients with different cultural backgrounds for ensuring good quality of care and sensitize GPs for the caring of the migrant population.

\section{Acknowledgments}

We would like to thank Dr Zekeriya Aktürk from the Department of General Practice of Trakya University in Edirne, Turkey, for providing the Turkish version of the EUROPEP instrument. We also like to thank the participating practices and patients. Finally, we also gratefully thank Sarah Berger, a native speaker, for reviewing this manuscript.

\section{Disclosure}

The authors report no conflicts of interest in this work.

\section{References}

1. Dowd BE, Kralewski JE, Kaissu AA, Irrgang SJ. Is patient satisfaction influenced by the intensity of medical resource use by their physicians? Am J Manag Care. 2009;15(5):e16-e21.

2. Vingerhoets E, Wensing M, Grol R. Feedback of patients' evaluation of general practice care: a randomised trial. Qual Health Care. 2001;10: 224-228.

3. Marcinowicz L, Chlabicz S, Grebowski R. Understanding patient satisfaction with family doctor care. J Eval Clin Pract. 2010;16:712-715.

4. Hohne A, Jedlitschka K, Hobler D, Landenberger M. [General practitionercentered health-care in Germany. The general practitioner as gatekeeper]. Gesundheitswesen. 2009;71:414-422.

5. Gutachten 2009 des Sachverständigenrates zur Begutachtung der Entwicklung im Gesundheitswesen [In Expert Report 2009 for Assessment of Developments in Health Care]. Bonn: Deutscher Bundestag: 311-333. German.

6. Migrationsbericht 2009 des Bundesamtes für Migration und Flüchtlinge im Auftrag der Bundesregierung [Migration report commissioned by the Federal Government 2009]. Berlin: Bundesamt für Migration und Flüchtlinge und Bundesministerium des Inneren; 2009:218-219. German.

7. Razum O, Zeeb H, Meesmann U, et al. Migration und Gesundheit. Schwerpunktbericht der Gesundheitsberichterstattung des Bundes. [Migration and health. A report from health report of the Federal Government]. Berlin: Robert-Koch-Institut; 2008;107-120. German.

8. Bungartz J, Joos S, Steinhäuser J, Szecsenyi J, Freund T. [Challenges and potentials of primary care in a multicultural society]. Bundesgesundheitsbl Bundesgesundheitsforsch Bundesgesundheitsschutz. 2011; 54:1179-1186. 
9. Sahlan S, Wollny A, Brockmann S, Fuchs A, Altiner A. Reducing unnecessary prescriptions of antibiotics for acute cough: adaptation of a leaflet aimed at Turkish immigrants in Germany. BMC Fam Pract. 2008;9:57.

10. Von Ferber L, Köster I, Celayir-Erdogan N. [Turkish and German patients of general practitioners - diseases, drug expectations and drug prescriptions]. Gesundheitswesen. 2003;64:304-311.

11. Dagdeviren N, Akturk Z. An evaluation of patient satisfaction in Turkey with the EUROPEP Instrument. Yonsei Medial Journal. 2004;45:23-28.

12. Grol R, Wensing M. Patients Evaluate General/Family Practice: The EUROPEP Instrument. Nijmegen: World Organization of Family Doctors (WONCA)/European Association for Quality in Family Practice; 2000.

13. Schenk L, Bau AM, Borde T, et al. [A basic set of indicators for mapping migrant status. Recommendations for epidemiological practice]. Bundesgesundheitsbl Bundesgesundheitsforsch Bundesgesundheitsschutz. 2006;49(9):853-860.

14. Goetz K, Campbell S, Willms S, Rochon J, Klingenberg A, Szecsenyi J. How do chronically ill patients evaluate their medical care? An observational study with 46919 patient in 676 primary care practices of direct relevance to person-centered medicine. Int J Pers Cent Med. 2011;1: 338-346.

15. Goetz K, Szecsenyi J, Klingenberg A, Brodowski M, Wensing M, Campbell SM. Evaluation of patient perspective on quality of oral health care in Germany - an exploratory study. Int Dent J. 2013;63: 317-323.

16. Kersnik J. An evaluation of patient satisfaction with family practice care in Slovenia. Int J Qual Health Care. 2000;12:143-147.

17. Aktürk Z, Atesoglu D, Ciftci E. Patient satisfaction with family practice in Turkey: three-year trend from 2010 to 2012. Eur J Gen Pract. 2015:1-8. [Epub ahead of print].

18. Street RL, O’Malley KJ, Cooper LA, Haidet P. Understanding concordance in patient-physician relationships: personal and ethnic dimensions of shared identity. Ann Fam Med. 2008;6(3):198-205.
19. Strumpf EC. Racial/ethnic disparities in primary care: the role of physician-patient concordance. Med Care. 2011;49:496-503.

20. Priebe S, Sandhu S, Dias S, et al. Good practice in health care for migrants: views and experiences of care professionals in 16 European countries. BMC Public Health. 2011;11:187.

21. Harmsen JA, Bernsen RM, Bruijnzeels MA, Meeuwesen L. Patients' evaluation of quality of care in general practice: what are the cultural and linguistic barriers? Patient Educ Couns. 2008;72:155-162.

22. Bungartz J, Uslu S, Natanzon I, Joos S. Utilization of the family practitioner of Turkish and German patients - a qualitative study. Z Allg Med. 2011;87:115-122.

23. Sorkin DH, Ngo-Metzger Q, De Alba I. Racial/ethnic discrimination in health care: impact on perceived quality of care. J Gen Intern Med. 2010;25:390-396.

24. Baker R, Boulton M, Windridge K, Tarrant C, Bankart J, Freeman GK. Interpersonal continuity of care: a cross-sectional survey of primary care patients' preferences and their experiences. Br J Gen Pract. 2007;57:283-290.

25. Mead N, Roland M. Understanding why some ethnic minority patients evaluate medical care more negatively than white patients: a cross sectional analysis of a routine patient survey in English general practices. BMJ. 2009;339:b3450.

26. Salisbury C, Wallace M, Montgomery AA. Patients' experience and satisfaction in primary care: secondary analysis using multilevel modeling. BMJ. 2010;341:c5004.

27. Dagdeviren $N$, Akturk $Z$. An evaluation of patient satisfaction in turkey with the EUROPEP instrument. Yonsei Med J. 2004;45:23-28.

28. Sheikh A. Ethnic minorities and their perceptions of the quality of primary care. BMJ. 2009;339:b3797.

29. Petek D, Künzi B, Kersnik J, Szecsenyi J, Wensing M. Patients' evaluations of European general practice - revisited after 11 years. Int J Qual Health Care. 2011;23:621-628.

30. Grol R, Wensing M, Mainz J, et al. Patients in Europe evaluate general practice care: an international comparison. Br J Gen Pract. 2000;50: $882-887$.
Patient Preference and Adherence

\section{Publish your work in this journal}

Patient Preference and Adherence is an international, peer-reviewed, open access journal that focuses on the growing importance of patient preference and adherence throughout the therapeutic continuum. Patient satisfaction, acceptability, quality of life, compliance, persistence and their role in developing new therapeutic modalities and compounds to optimize

\section{Dovepress}

clinical outcomes for existing disease states are major areas of interest for the journal. This journal has been accepted for indexing on PubMed Central. The manuscript management system is completely online and includes a very quick and fair peer-review system, which is all easy to use. Visit http://www. dovepress.com/testimonials.php to read real quotes from published authors. 